\title{
Effect of intermittent preventive treatment of malaria on health and education in schoolchildren: a cluster-randomised, double-blind, placebo- controlled trial
}

\section{Citation}

Clarke, Siân E, Matthew CH Jukes, J Kiambo Njagi, Lincoln Khasakhala, Bonnie Cundill, Julius Otido, Christopher Crudder, Benson BA Estambale, and Simon Brooker. 2008. Effect of intermittent preventive treatment of malaria on health and education in schoolchildren: a cluster-randomised, double-blind, placebo-controlled trial. Lancet 372(9633): 127-138.

\section{Published Version}

doi://10.1016/S0140-6736(08)61034-X

\section{Permanent link}

http://nrs.harvard.edu/urn-3:HUL.InstRepos:4553286

\section{Terms of Use}

This article was downloaded from Harvard University's DASH repository, and is made available under the terms and conditions applicable to Open Access Policy Articles, as set forth at http:// nrs.harvard.edu/urn-3:HUL.InstRepos:dash.current.terms-of-use\#OAP

\section{Share Your Story}

The Harvard community has made this article openly available.

Please share how this access benefits you. Submit a story. 


\title{
Effect of intermittent preventive treatment of malaria on health and education in schoolchildren: a cluster-randomised, double-blind, placebo-controlled trial
}

\author{
Siân E Clarke ${ }^{a^{*}}$, Matthew CH Jukes ${ }^{b}$, J Kiambo Njagic, Lincoln Khasakhalad, Bonnie \\ Cundill $^{\mathrm{a}}$, Julius Otido ${ }^{\mathrm{e}}$, Christopher Crudder ${ }^{\mathrm{a}}$, Benson BA Estambale ${ }^{\mathrm{e}}$, and Simon \\ Brookera,f \\ ${ }^{a}$ London School of Hygiene and Tropical Medicine, London, UK. \\ ${ }^{b}$ Harvard University, Cambridge, MA, USA. \\ ${ }^{c}$ Division of Malaria Control, Ministry of Health, Nairobi, Kenya. \\ ${ }^{d}$ African Mental Health Foundation, Nairobi, Kenya. \\ ${ }^{e}$ Institute of Tropical and Infectious Diseases, University of Nairobi, Kenya.

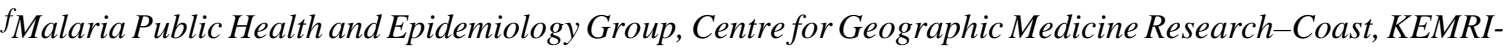 \\ Wellcome Trust Collaborative Programme, Nairobi, Kenya.
}

\section{Summary}

Background-Malaria is a major cause of morbidity and mortality in early childhood, yet its consequences for health and education during the school-age years remain poorly understood. We examined the effect of intermittent preventive treatment (IPT) in reducing anaemia and improving classroom attention and educational achievement in semi-immune schoolchildren in an area of high perennial transmission.

Methods-A stratified, cluster-randomised, double-blind, placebo-controlled trial of IPT was done in 30 primary schools in western Kenya. Schools were randomly assigned to treatment (sulfadoxinepyrimethamine in combination with amodiaquine or dual placebo) by use of a computer-generated list. Children aged 5-18 years received three treatments at 4-month intervals (IPT $n=3535$, placebo $\mathrm{n}=3223$ ). The primary endpoint was the prevalence of anaemia, defined as a haemoglobin concentration below $110 \mathrm{~g} / \mathrm{L}$. This outcome was assessed through cross-sectional surveys 12 months post-intervention. Analysis was by both intention to treat, excluding children with missing data, and per protocol. This study is registered with ClinicalTrials.gov, number NCT00142246.

Findings-2604 children in the IPT group and 2302 in the placebo group were included in the intention-to-treat analysis of the primary outcome; the main reason for exclusion was loss to followup. Prevalence of anaemia at 12 months averaged 6.3\% in the IPT group and $12.6 \%$ in the placebo group (adjusted risk ratio $0 \cdot 52,95 \%$ CI $0 \cdot 29-0 \cdot 93 ; \mathrm{p}=0.028$ ). Significant improvements were also seen in two of the class-based tests of sustained attention, with a mean increase in code transmission

2008 Elsevier Ltd. All rights reserved..

*Correspondence to: Dr Siân Clarke, London School of Hygiene and Tropical Medicine, Keppel Street, London WC1E 7HT, UK sian.clarke@1shtm.ac.uk.

This document was posted here by permission of the publisher. At the time of deposit, it included all changes made during peer review, copyediting, and publishing. The U.S. National Library of Medicine is responsible for all links within the document and for incorporating any publisher-supplied amendments or retractions issued subsequently. The published journal article, guaranteed to be such by Elsevier, is available for free, on ScienceDirect. 
test score of 6.05 (95\% CI 2.83-9.27; $\mathrm{p}=0.0007)$ and counting sounds test score of 1.80 (0.19-3.41; $\mathrm{p}=0.03$ ), compared with controls. No effect was shown for inattentive or hyperactive-compulsive behaviours or on educational achievement. The per-protocol analysis yielded similar results. 23 serious adverse events were reported within 28 days of any treatment (19 in the IPT group and four in the placebo group); the main side-effects were problems of balance, dizziness, feeling faint, nausea, and/or vomiting shortly after treatment.

Interpretation-IPT of malaria improves the health and cognitive ability of semi-immune schoolchildren. Effective malaria interventions could be a valuable addition to school health programmes.

Funding-Gates Malaria Partnership, the Norwegian Education Trust Fund and multidonor Education Development Programme Fund of the World Bank, DBL Centre for Health Research and Development, and the Wellcome Trust.

\section{Introduction}

Children living in areas of high malaria transmission rapidly acquire immunity to malaria in early childhood; by the time they reach school age, the risk of clinical attacks and death has reduced. However, many school-aged children continue to harbour asymptomatic parasitaemia, which can cause anaemia. Although malaria might have an adverse effect on cognition and education outcomes, evidence for this has so far been lacking, and the case for school-based malaria control has not been established. Historically, malaria chemoprophylaxis given to African schoolchildren was associated with lower rates of malaria parasitaemia and severe anaemia, fewer clinical attacks and malaria deaths, and reduced school absenteeism because of malaria. One randomised trial has investigated the effect of clinical malaria on educational outcomes and provides evidence that school performance is related to the cumulative effect of previous malaria attacks and that weekly chemoprophylaxis with chloroquine can improve school examination scores in Sri Lankan children. However, this approach faces operational challenges, and could prove less effective in sub-Saharan Africa, where subclinical infections predominate. An alternative strategy is intermittent preventive treatment (IPT), which involves the periodic mass administration of a full therapeutic course of an antimalarial drug, irrespective of infection status. We undertook a randomised controlled trial in western Kenya to investigate the efficacy of school-based IPT in reducing anaemia and improving classroom attention and educational achievement.

\section{Methods}

\section{Participants}

This stratified, cluster-randomised, double-blind, placebo-controlled trial was done between March, 2005, and March, 2006, in primary schools in Bondo district, western Kenya. Malaria transmission is intense and perennial in this region, with two seasonal peaks (March-May and November-December). By school age, clinical incidence declines to 0.25 episodes per child per year, although up to $50 \%$ of schoolchildren have asymptomatic malaria parasitaemia.

Rural primary schools with 150 children or more, and over 15 children per class were eligible for inclusion. Schools located within $5 \mathrm{~km}$ from Lake Victoria were excluded to minimise confounding by Schistosoma mansoni. Meetings were held in participating schools to explain the nature and purpose of the trial to parents or legal guardians, and written informed consent was obtained. Schoolchildren with parental consent and no history of adverse reaction to sulfabased drugs were eligible for recruitment. Children with a haemoglobin concentration of less than $70 \mathrm{~g} / \mathrm{L}$ at baseline, or known or suspected to be homozygous for sickle-cell trait or pregnant were not enrolled. 
The protocol was approved by the ethics review boards of Kenyatta National Hospital, Kenya; London School of Hygiene and Tropical Medicine, UK; and Danish National Committee on Medical Research Ethics, Denmark. Permissions were obtained from the Kenyan Ministry of Education, the District Education and Health Authorities, and head teachers. An independent data safety monitoring board monitored the trial and approved the analysis plan.

\section{Procedures}

We stratified schools into three groups according to school examination performance in previous years, to account for differences in school quality and socioeconomic environment. Ten schools were randomly selected from each school-performance stratum, and within each stratum schools were randomly allocated to one of six coded drug groups by use of block randomisation (three pairs of either active drugs or dual placebo) according to a computergenerated random number list by an investigator (SEC) blind to drug group.

Children in intervention schools received IPT with one dose of sulfadoxine-pyrimethamine and three daily doses of amodiaquine on three occasions within a 12-month period (once each school term). IPT was first given in May, 2005, coinciding with a seasonal peak in transmission, and then repeated in September, 2005, and January, 2006. Children absent from school were not treated. Children in control schools received dual placebo tablets over 3 consecutive days on each occasion.

Study drugs and placebos were manufactured by Cosmos Limited (Nairobi, Kenya) and labelled according to six coded drug groups. The code was held by the manufacturers and the data safety monitoring board, and revealed to the investigators only after completion of the statistical analysis. Dosage was by age. Participants were observed for $30 \mathrm{~min}$ after drug intake and treatment re-administered once more if spitting or vomiting occurred. Active drugs and placebos were similar in size and shape, but differed in taste. To preserve blinding, staff responsible for measuring health or education outcomes were unaware of drug group allocation, and analysis was done by a statistician with no previous involvement in the trial. Adverse events were monitored by the study team for 3 days after each treatment, and a further 28 days thereafter using a passive surveillance system in schools and local health centres. Travel costs were reimbursed and treatment charges waived. Adverse effects were monitored until the event was cured or had stabilised.

Incidence of clinical attacks was not measured, although a blood slide was prepared in children presenting with fever during school visits, and slide-positive cases were treated for malaria in accordance with national guidelines. Children with a haemoglobin concentration less than 70 $\mathrm{g} / \mathrm{L}$ were given a course of haematinics. $S$ mansoni-positive children received one dose of praziquantel $(40 \mathrm{mg} / \mathrm{kg}$ ). Children in all schools (intervention and placebo) received mass treatment twice a year for soil-transmitted helminth infections with one dose of albendazole (400 mg).

We investigated whether intermittent clearance of malaria parasitaemia would increase haemoglobin concentrations and, as a consequence, reduce anaemia and contribute to improved attention in class and educational performance. The primary endpoint was the prevalence of anaemia, defined as a haemoglobin concentration of less than $110 \mathrm{~g} / \mathrm{L}$, after 12 months of intervention. Secondary endpoints included prevalence and intensity of Plasmodium falciparum infection, mean haemoglobin concentration, sustained attention, and educational achievement.

Cross-sectional surveys were done in all schools in March, 2006, approximately 6 weeks after the last treatment. Finger-prick blood samples were obtained from all children with consent (aged 5-18 years) to assess haemoglobin concentration with a portable photometer (Hemocue, 
Angelholm, Sweden). Blood slides prepared for malaria were declared negative only after examination of 100 high-powered fields. Data on covariates, including bednet use and household socioeconomic status were obtained through a questionnaire administered to children in classes 2-7 (aged 7-17 years) during the final survey. Height and weight were measured, and anthropometric indices calculated. For logistical reasons, only children in classes 5 and 6 were asked to provide stool samples, which were examined microscopically for helminth eggs by use of the Kato-Katz technique.

The effect of the intervention on cognitive abilities was investigated primarily by comparing differences in test scores of sustained attention given to a cohort of children in classes 5 and 6 (aged 11-16 years). This group was selected for testing because they were old enough to understand the test instructions. Secondary education outcomes included behaviour in class and educational achievement.

Two tests of sustained attention were undertaken on the day preceding health assessments. Both tests were adapted from the TEA-Ch (tests of everyday attention for children) battery for group administration in groups of 15 or fewer, and given by a psychologist already trained in doing these tests. The tests involved listening to a tape and identifying different sounds (counting sounds) and numbers (code transmission). In the counting sounds tasks children were required to count a series of electronic beeps played on the tape recorder, with varying delays of 0.3-10 seconds between sounds. Sustained attention was required to keep track of the number of sounds counted during delays and to be prepared for bursts of several consecutive sounds. In the code transmission tasks, a list of digits was read out aloud at the speed of one per second. Children were required to listen out for a "code"- two consecutive occurrences of the number 5-and then record the two numbers that preceded the code. A second test, included in the final survey, required children to recall the three numbers that preceded the code. Before each test children were given a warm-up activity to familiarise them with the tape recorder, and three practice exercises. Internal reliability was high for both tests (Cronbach $\alpha>0.7$ for counting sounds and $\alpha>0.8$ for code transmission).

Classroom behaviour was assessed by teacher ratings of inattentive and hyperactive-impulsive behaviours in eight children randomly selected (by MCHJ) from each class by use of a computer-generated random number list. Behaviours were selected from the early childhood attention deficit disorder scale. Behaviours that were weakly correlated $(<0 \cdot 3)$ with the sum of other behaviour scores in piloting were deemed not to be strongly related to the overall trait and were dropped from the final instrument. Internal reliability was high (Cronbach $\alpha>0 \cdot 8$ ). Assessment of educational achievement focused on learning which occurred towards the end of the intervention year, when the cumulative effect of repeated malaria treatment should have achieved maximum improvements in classroom attention. Knowledge of a content-based subject, taught during the last school term of the study, was measured in the two intervention groups. In January, 2006, teachers attended a 1-day training seminar to standardise the curriculum and teaching methods for social studies in classes 6 and 7. Children were tested at the end of the school term. A multiple choice exam was developed for each class. Internal reliability was adequate for both class exams (Cronbach $\alpha=0.62$ for class 6 and $\alpha=0.59$ for class 7).

\section{Statistical analysis}

On the basis of an observed anaemia prevalence of $38 \%$ at baseline and coefficient of variation between clusters of $0 \cdot 27$, a sample size of 12 schools with a total of 889 children in each arm was estimated to provide $80 \%$ power to detect a $30 \%$ reduction in the prevalence of anaemia in the intervention group compared with placebo at $5 \%$ level of significance. For the cognitive and education tests, where an intraclass correlation of 0.20 was assumed, a minimum of 15 schools per arm with 60 children assessed per school were needed to provide $80 \%$ power to 
detect an effect size of 0.25 in the intervention group compared with placebo at $5 \%$ level of significance.

Data were analysed by intention to treat, excluding those children with missing data. A perprotocol analysis was also done, including only children treated on all three rounds and who completed the full 3-day regimen on each occasion, totalling 9 days of treatment. Children who received either haematinics for severe anaemia or active antimalarials for clinical malaria, or both, at any point during the study were excluded from the per-protocol analysis.

The effect of the intervention was analysed with methods appropriate for a cluster-randomised trial. The prevalence, or mean, in each school was calculated and the unadjusted risk ratio, or mean difference (intervention-control), estimated in each stratum. An overall estimate of the effect of IPT was obtained by taking a weighted average of the stratum-specific estimates, the weights proportional to the number of schools per stratum, and 95\% CIs were adjusted for observed between-school variance (Hayes R, London School of Hygiene and Tropical Medicine, personal communication). Effect size for cognition was calculated by dividing the difference in the mean cluster-level summaries by the standard deviation of individual values averaged across study arms. Formal hypothesis testing was done with stratified unpaired $t$ tests. Standard individual-level regression analysis, which incorporated stratum as a fixed effect and all covariates, suspected a priori to be confounders or effect modifiers, except the intervention effect, was used to calculate cluster-level expected values. Observed and expected values were compared by computing a residual, based on the ratio of observed to expected or the difference between observed and expected, for each school. Adjustment for covariates was undertaken replacing school-level means and proportions with covariate-adjusted residuals. Additionally, the effect of intervention was assessed with adjustment for baseline characteristics among those children for whom baseline data were available. All analyses were undertaken using STATA version 9.2.

This study is registered with ClinicalTrials.gov, number NCT00142246.

\section{Role of the funding source}

The sponsor of the study had no role in study design, data collection, analysis, interpretation, or writing of the report. SEC, MCHJ, BC, and SB had full access to the data and made the final decision to submit for publication.

\section{Results}

The trial profile is shown in figure $1.4916(73 \%)$ of 6758 school children enrolled in the trial were examined in the post-intervention survey 12 months later. The numbers of children lost to follow-up were similar in IPT intervention and placebo schools (26\% and $28 \%$, respectively). Health outcomes for children in the intervention group $(\mathrm{n}=2611)$ and placebo group $(\mathrm{n}=2305)$ were analysed according to intention to treat. Most children examined post-intervention had received treatment on all three occasions (more than 7 days of treatment were completed by 1946 [75\%] and 1990 [86\%] in each group), although only 1070 (41\%) of children in the intervention group and $1394(60 \%)$ in the placebo group had received treatment on all 9 days and were included in the per-protocol analysis of health outcomes. Children lost to follow-up and those who received incomplete treatment had similar baseline characteristics to children included in the per-protocol analysis (table 1 and table 2). Children in the IPT intervention and placebo groups were similar, although those in the IPT intervention group had slightly better nutritional status at baseline and fewer children were anaemic. Imbalances in helminth infection at baseline were successfully corrected with anthelmintic mass treatment and no marked differences in prevalence of helminth infections existed between intervention and placebo groups at follow-up. 818 children ( $76 \%$ of the original education cohort in classes 5 
and 6 at baseline) participated in the tests of sustained attention post-intervention (436 in the IPT group, 382 in the placebo group). Children lost to follow-up were similar to those examined post-intervention (data not shown). Study endpoints and nutritional status in the IPT and placebo groups were similar at baseline, with slight differences in socioeconomic background (table 2 and table 3 ).

At follow-up, the prevalence of anaemia among schoolchildren in the IPT intervention group was significantly lower than in the placebo group (table 4). Results of the intention-to-treat analysis show that the protective efficacy of the intervention against anaemia was $48 \%$ (95\% CI $8-71 ; \mathrm{p}=0.028$; table 4$)$. The adjusted risk difference was $-0.06(-0.01$ to -0.11$)$, equating to one case of anaemia prevented for every 16 children treated with IPT (95\% CI 9-91 children). There were also fewer cases of severe anaemia (haemoglobin $<70 \mathrm{~g} / \mathrm{L}$ ) in the IPT intervention group than in the placebo group (four and 16 cases, respectively). Similarly, post-intervention mean haemoglobin concentration was significantly higher among children in the intervention group than among controls (table 4); adjusted difference 5.01 g/L (95\% CI 1.62-8.41; $\mathrm{p}=0.005$ ). IPT seemed to benefit children across the whole distribution of haemoglobin concentrations, as shown by the different distributions between the two groups (figure 2). Prevalence of $P$ falciparum parasitaemia was lower among children receiving IPT than in those in the placebo group, with a protective efficacy against $P$ falciparum infection of $89 \%$ (95\% CI 73-95; $\mathrm{p}=0.0002$; table 4$)$. The adjusted risk difference was -0.35 ( 0.30 to -0.41$)$, equating to an average of one infection prevented for every three children treated with IPT (95\% CI 2-4 children). Among the subset of children infected with $P$ falciparum at follow-up, mean parasite density was similar in the two groups $(\mathrm{p}=0 \cdot 108)$.

Results of the per-protocol analysis, which included only children who received complete treatment during each treatment round, were similar to those of the intention-to-treat analysis (table 4). Analysis was also repeated on the subgroup of 2471 children for whom haemoglobin data at baseline were available, and yielded similar results (data not shown), confirming that the observed differences are not attributable to slight baseline imbalances in nutritional status. Although no formal test of interaction was made, we also undertook prespecified exploratory analyses to investigate the effect of intervention stratified by age, sex, and anaemia status at baseline. The effect of IPT on anaemia did not differ by age-group (data not shown), but the effect in girls was slightly greater than in boys (data not shown). An increase in mean haemoglobin was seen in all subgroups of children, including those who were not anaemic at baseline (adjusted difference $7 \cdot 42 \mathrm{~g} / \mathrm{L}, 95 \%$ CI 3.05-11.79; $\mathrm{p}=0 \cdot 0018$ ).

At follow-up, scores for sustained attention were higher in the IPT intervention group than among controls for the counting sounds test (adjusted mean difference 1.80 [0.19-3.41; $\mathrm{p}=0.03$; table 5) and the code transmission test (adjusted mean difference 6.05 [2.83-9.27]; $\mathrm{p}=0.0007$ ). The effect size was $1.22(95 \%$ CI $0.003-0.35)$ in the counting sounds test and $0.86(0.09-0.88)$ in the code transmission test. There was no difference in mean score for inattentive or hyperactive-compulsive behaviours (table 5) or mean educational achievement test scores (table 6) between study groups.

Seven children died during the 12-month intervention period: two in the IPT intervention group and five in the placebo group. Cause of death was investigated, but could not be reliably ascertained in all cases. 23 serious adverse events were reported within 28 days after any mass treatment (includes children admitted for observation): 19 in the intervention group (of which three were judged to be possibly associated with treatment) and four in the control group. The most common serious adverse events were problems of balance, dizziness, feeling faint, nausea, or vomiting, which all occurred within $5 \mathrm{~h}$ of treatment. There was only one report of a severe skin reaction, which occurred in the placebo group. A further 13 adverse events were graded as moderate: six in the intervention group and seven in the placebo group. Mild events, 
such as nausea, headache, and prurititis, were more frequent among children receiving active drugs than among controls (49 and 33 reports, respectively).

\section{Discussion}

This trial has shown that school-based delivery of IPT once per term markedly reduced the prevalence of anaemia and asymptomatic parasitaemia in semi-immune schoolchildren in Kenya. We also show a beneficial effect of malaria treatment on sustained attention of schoolchildren. Although only $73 \%$ of enrolled children were followed up, there were no marked differences in background characteristics or follow-up rates between study groups, suggesting that treatment effects were not caused by sample bias. Children receiving IPT were less likely to complete the full 3-day regimen, possibly because of the bitter taste of amodiaquine, but there was little evidence that this introduced bias since the characteristics of children who received complete and incomplete treatment were similar. Additionally, twice yearly anthelmintic treatment was given to all children (intervention and control), reducing helminth infection and anaemia in both groups from initial baseline levels. The resultant similarities in levels of helminth infection between study groups at follow-up, as well as nutritional status, provide convincing evidence that the effect on anaemia was mainly caused by reductions in malaria parasitaemia.

Our findings are consistent with earlier observations that insecticide-treated bednet use is associated with reduced anaemia in adolescent schoolgirls, suggesting that malaria control could have an important role in preventing anaemia in school-aged children. The size of the protective effect of IPT against anaemia is markedly greater than the protective effects seen in previous trials of anthelmintic treatment. The effect is also comparable with, or larger than, reductions in the rates of anaemia seen following iron supplementation. Notably, previous trials often report that either young children or anaemic children benefit most from intervention. However, in our study the protective effect of the intervention against anaemia did not differ among age-groups, and significant improvements in mean haemoglobin concentrations were seen in children who were not classified as anaemic at baseline. This effect could have been achieved through the clearance of asymptomatic infections that would otherwise go untreated, thereby providing a window for haematological recovery. Decreased rates of destruction and removal of parasitised red blood cells, and improvements in the rate of erythrocyte production in the bone marrow during parasite-free periods might contribute to improvements in haemoglobin concentration and anaemia. Long-acting drugs, such as sulfadoxinepyrimethamine, could also provide a period of prophylaxis immediately after treatment.

Concerns that chemoprevention might impede the development of antimalarial immunity and lead to rebound morbidity might be less relevant in the age-group studied here, especially under intense transmission where early exposure promotes rapid acquisition of immunity before reaching school age. Treatment at 4-month intervals permits reinfection, maintaining levels of exposure-dependent immunity. Studies undertaken after completion of the trial showed the IPT strategy to be well accepted by teachers, parents, and schoolchildren (data not shown). Few serious adverse events attributable to study medication were recorded, and most symptoms were mild and self-limiting. Nonetheless, their occurrence in healthy asymptomatic children is not desirable.

Malaria early in life has been shown to impair later cognitive performance and clinical malaria affects school performance. Our results show that asymptomatic infection can also affect cognitive performance and that treatment against asymptomatic malaria improves sustained attention. However, by contrast with the Sri Lankan study, we did not find an improvement in educational achievement. Mean scores were generally low, suggesting that examined knowledge improved insufficiently in both placebo and intervention groups for a difference 
between them to be detected. Other possible reasons include low statistical power $(<20 \%)$ because of greater than expected school-level clustering of educational achievement scores, short duration of follow-up, and the limited number of schoolchildren tested. Clinical attacks are less common in our population, which might also explain the difference between this and the Sri Lankan study.

The mechanism for the effect on cognition is not known, but it is possible that raised haemoglobin concentrations had a role in improving attention. There is strong evidence that iron-deficiency anaemia leads to impaired cognitive function, although the cognitive effect of anaemia due to causes other than iron deficiency is less well understood. Among many school health and nutrition interventions previously assessed, only iron supplementation and malaria prevention (in Sri Lanka and the current study) have shown substantial improvements in cognitive function of around $0.5 \mathrm{SD}$ or greater.

This large field trial, using a randomised design, enabled the effect of malaria on sustained attention to be demonstrated, and provides strong evidence of a link between asymptomatic malaria and cognition. We did not, however, do an extensive battery of cognitive tests, and cannot determine whether asymptomatic malaria affects other aspects of cognitive function. Neither did we examine the effect of clinical attacks or absenteeism on anaemia or cognitive function. In other settings where the incidence of clinical attacks in schoolchildren is higher, this could adversely affect school performance and absenteeism. Knowledge of the effect of malaria on school performance and education is far from complete, but our findings provide sufficient evidence to indicate that this warrants more attention.

School health programmes provide an effective vehicle to control anaemia and improve educational outcomes of school-aged children living in developing countries. The pronounced effects of the IPT intervention on anaemia and malaria parasitaemia, and the effect on sustained attention, highlight the issue of the continued, and often unrecognised, malaria burden among school-aged children in Africa and the potential of school-based programmes for tackling the problem. Our findings also illustrate the possible gains of integrating malaria control into broader school health programmes. These results now need to be replicated in different epidemiological settings. Further research is also needed to investigate the operational feasibility of the approach, and any long-term educational benefits.

\section{Acknowledgements}

Acknowledgments

The trial was funded by the Gates Malaria Partnership, which is supported by a grant from the Bill \& Melinda Gates Foundation. Additional funding was provided by the Norwegian Education Trust Fund and multidonor Education Development Programme Fund (both administered by the Africa Region Human Development Department, World Bank, and which contribute to the World Bank Africa Program for Education Impact Evaluation and the Malaria Impact Evaluation Program); and DBL Centre for Health Research and Development. SB is supported by the Wellcome Trust through a Career Development Fellowship (081673). We thank the schoolchildren for their participation in the study; the school teachers, district education, and health officials for their support and cooperation; and members of the field research team. We also thank the members of the data safety monitoring board (David Lalloo, Bob Snow, Yin Bun Cheung, and Rashid Juma); Harparkash Kaur for undertaking the drug quality testing; and Brian Greenwood, Geoff Targett, and Pascal Magnussen for comments on the manuscript.

\section{Contributors}

SEC, MCHJ, BBAE, and SB designed the study. MCHJ developed the cognitive tests and MCHJ and LK coordinated data collection of the cognitive and educational data. BBAE and JKN were responsible for administrative logistics. SEC, JKN, JO, and CC coordinated delivery of the intervention and supervised data collection teams. JO was the clinical officer and CC was responsible for data management. SEC, MCHJ, BC, and SB developed the analysis plan, and BC analysed the data. SEC and SB wrote the manuscript, and all authors commented on the final draft.

\section{Conflict of interest statement}


We declare that we have no conflict of interest.

\section{References}

1. Snow R, Marsh K. The consequences of reducing transmission of Plasmodium falciparum infection in Africa. Adv Parasitol 2002;52:235-264. [PubMed: 12521262]

2. Bloland PB, Boriga DA, Ruebush TK. Longitudinal cohort study of the epidemiology of malaria infections in an area of intense malaria transmission II. Descriptive epidemiology of malaria infection and disease among children. Am J Trop Med Hyg 1999;60:641-648. [PubMed: 10348241]

3. Clarke SE, Brooker S, Njagi JK. Malaria morbidity amongst schoolchildren living in two areas of contrasting transmission in western Kenya. Am J Trop Med Hyg 2004;71:732-738. [PubMed: 15642962]

4. Kurtzhals JA, Addae MM, Akanmori BD. Anaemia caused by asymptomatic Plasmodium falciparum infection in semi-immune African schoolchildren. Trans R Soc Trop Med Hyg 1999;93:623-627. [PubMed: 10717750]

5. Holding PA, Snow RW. Impact of Plasmodium falciparum malaria on performance and learning: review of the evidence. Am J Trop Med Hyg 2001;64(suppl 1-2):68-75. [PubMed: 11425179]

6. Lalloo DG, Olukoya P, Olliaro P. Malaria in adolescence: burden of disease, consequences, and opportunities for intervention. Lancet Infect Dis 2006;6:780-793. [PubMed: 17123898]

7. Bundy DA, Lwin S, Osika JS, McLaughlin J, Pannenborg CO. What should schools do about malaria? Parasitol Today 2000;16:181-182. [PubMed: 10782071]

8. Brooker S, Guyatt H, Omumbo J, Shretta R, Drake L, Ouma J. Situation analysis of malaria in schoolaged children in Kenya: what can be done? Parasitol Today 2000;16:183-186. [PubMed: 10782073]

9. Brooker S, Clarke SE, Snow RW, Bundy DA. Malaria in African schoolchildren: options for control. Trans R Soc Trop Med Hyg 2008;102:304-305. [PubMed: 18313705]

10. Greenwood, BM. Malaria chemoprophylaxis in endemic regions. In: Targett, GAT., editor. Malaria: waiting for the vaccine. John Wiley \& Sons; Chichester: 1991. p. 83-104.

11. Geerligs PD, Brabin BJ, Eggelte TA. Analysis of the effects of malaria chemoprophylaxis in children on haematological responses, morbidity and mortality. Bull World Health Organ 2003;81:205-216. [PubMed: 12764517]

12. Colbourne MJ. The effect of malaria suppression in a group of Accra school children. Trans R Soc Trop Med Hyg 1955;49:356-369.

13. Fernando SD, Gunawardena DM, Bandara MR. The impact of repeated malaria attacks on the school performance of children. Am J Trop Med Hyg 2003;69:582-588. [PubMed: 14740872]

14. Fernando SD, De Silva D, Carter R, Mendis KN, Wickremasinghe R. A randomized, double-blind, placebo-controlled, clinical trial of the impact of malaria prevention on the educational attainment of school children. Am J Trop Med Hyg 2006;74:386-393. [PubMed: 16525095]

15. Greenwood BM. The use of antimalarial drugs to prevent malaria in the population of malaria-endemic areas. Am J Trop Med Hyg 2004;70:1-7. [PubMed: 14971690]

16. Beier JC, Oster CN, Onyango FK. Plasmodium falciparum incidence relative to entomological inoculation rates at a site proposed for testing malaria vaccines in western Kenya. Am J Trop Med Hyg 1994;50:529-536. [PubMed: 7911282]

17. Brooker S, Miguel EA, Waswa P. The potential of rapid screening methods for Schistosoma mansoni in western Kenya. Ann Trop Med Parasitol 2001;95:343-351. [PubMed: 11454244]

18. Manly, T.; Robertson, IH.; Anderson, V.; Nimmo-Smith, I. Test of Everyday Attention for Children: TEA-Ch. Thames Valley Test Company; Bury St Edmunds: 1999.

19. McCarney, SB. Early Childhood Attention Deficit Disorders Evaluation Scale. Hawthorne Educational Services Inc; Columbia, MO: 1995.

20. Hayes RJ, Bennett S. Simple sample size calculations for cluster-randomized trials. Int J Epidemiol 1999;28:319-326. [PubMed: 10342698]

21. Bennett S, Parpia T, Hayes R, Cousens S. Methods for the analysis of incidence rates in cluster randomized trials. Int J Epidemiol 2002;31:839-846. [PubMed: 12177032] 
22. Leenstra T, Phillips-Howard PA, Kariuki SK. Permethrin-treated bed nets in the prevention of malaria and anemia in adolescent schoolgirls in western Kenya. Am J Trop Med Hyg 2003;68(suppl 4):S86S93.

23. Stephenson LS, Latham MC, Kinoti SN, Kurz KM, Brigham H. Single dose metrifonate or praziquantel treatment in Kenyan children. I. Effects on Schistosoma haematobium, hookworm, hemoglobin levels, splenomegaly, and hepatomegaly. Am J Trop Med Hyg 1989;41:436-444. [PubMed: 2508501]

24. Beasley NM, Tomkins AM, Hall A. The impact of population level deworming on the hemoglobin levels of schoolchildren in Tanga, Tanzania. Trop Med Int Health 1999;4:744-750. [PubMed: 10588768]

25. Gulani A, Nagpal J, Osmond C, Sachdev HP. Effect of administration of intestinal anthelmintic drugs on haemoglobin: systematic review of randomised controlled trials. BMJ 2007;334:1095. [PubMed: 17434954]

26. Hall A, Roschnik N, Ouattara F. A randomised trial in Mali of the effectiveness of weekly iron supplements given by teachers on the haemoglobin concentrations of schoolchildren. Public Health Nutr 2002;5:413-418. [PubMed: 12003652]

27. Longfils P, Heang UK, Soeng H, Sinuon M. Weekly iron and folic acid supplementation as a tool to reduce anemia among primary school children in Cambodia. Nutr Rev 2005;63:39-45. [PubMed: 15762087]

28. Hettiarachchi M, Liyanage C, Wickremasinghe R, Hilmers DC, Abrams SA. The efficacy of micronutrient supplementation in reducing the prevalence of anaemia and deficiencies of zinc and iron among adolescents in Sri Lanka. Eur J Clin Nutr. 2007published online May 16.

29. Risonar MG, Tengco LW, Rayco-Solon P, Solon FS. The effect of a school-based weekly iron supplementation delivery system among anemic schoolchildren in the Philippines. Eur J Clin Nutr. 2007published online May 30

30. Menendez C, Fleming AF, Alonso PL. Malaria-related anaemia. Parasitol Today 2000;16:469-476. [PubMed: 11063857]

31. White NJ. Intermittent preventive treatment for malaria. PLoS Med 2005;2:e3. [PubMed: 15696210]

32. Kihara M, Carter JA, Newton C. The effect of Plasmodium falciparum on cognition: a systematic review. Trop Med Int Health 2006;11:386-397. [PubMed: 16553922]

33. Jukes MC, Pinder M, Grigorenko EL. Long-term impact of malaria chemoprophylaxis on cognitive abilities and educational attainment: follow-up of a controlled trial. PLoS Clin Trials 2006;1:e19. [PubMed: 17013430]

34. Grantham-McGregor S, Ani C. A review of studies on the effect of iron deficiency on cognitive development in children. J Nutr 2001;131(suppl 2):649S-666S. [PubMed: 11160596]

35. Soemantri AG, Pollitt E, Kim I. Iron deficiency anaemia and educational achievement. Am J Clin Nutr 1985;42:1221-1228. [PubMed: 4072957]

36. Jukes, MC.; Drake, LJ.; Bundy, DA. School health, nutrition and education for all: levelling the playing field. CABI Publishing; Wallingford, UK: 2007.

37. Bundy, DA.; Shaeffer, S.; Jukes, M. School based health and nutrition programs. In: Jamison, D.; Breman, JG.; Measham, AR., editors. Disease control priorities in developing countries. 2nd edn.. The World Bank and Oxford University Press; New York, USA: 2006. p. 1091-1108.

38. Brooker S, Akhwale W, Pullan R. Epidemiology of plasmodium-helminth co-infection in Africa: populations at risk, potential impact on anemia and prospects for combining control. Am J Trop Med Hyg 2007;77(suppl 6):88-98. [PubMed: 18165479] 


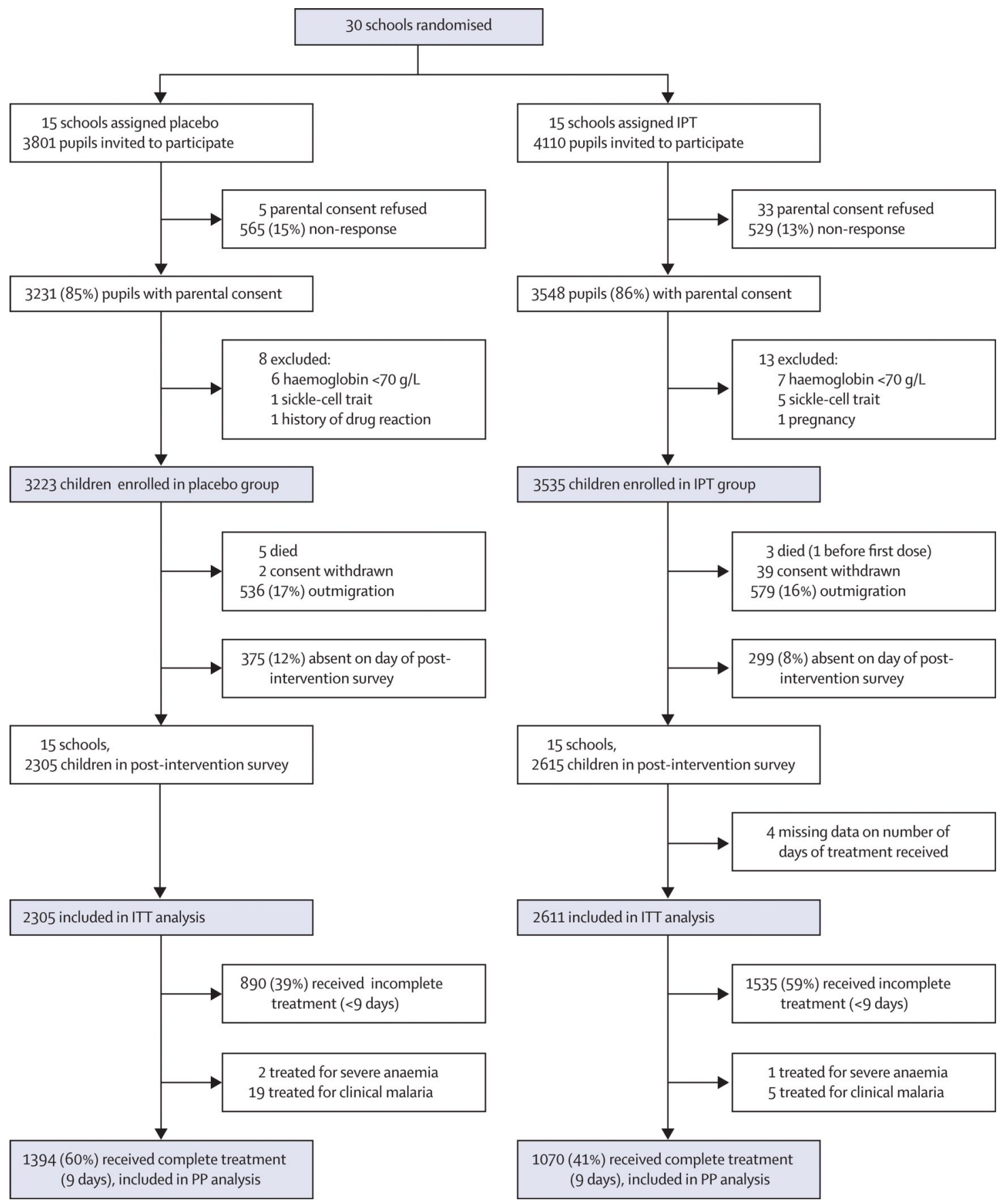

Figure 1.

Trial profile

ITT=intention-to-treat. $\mathrm{PP}=$ per-protocol. 


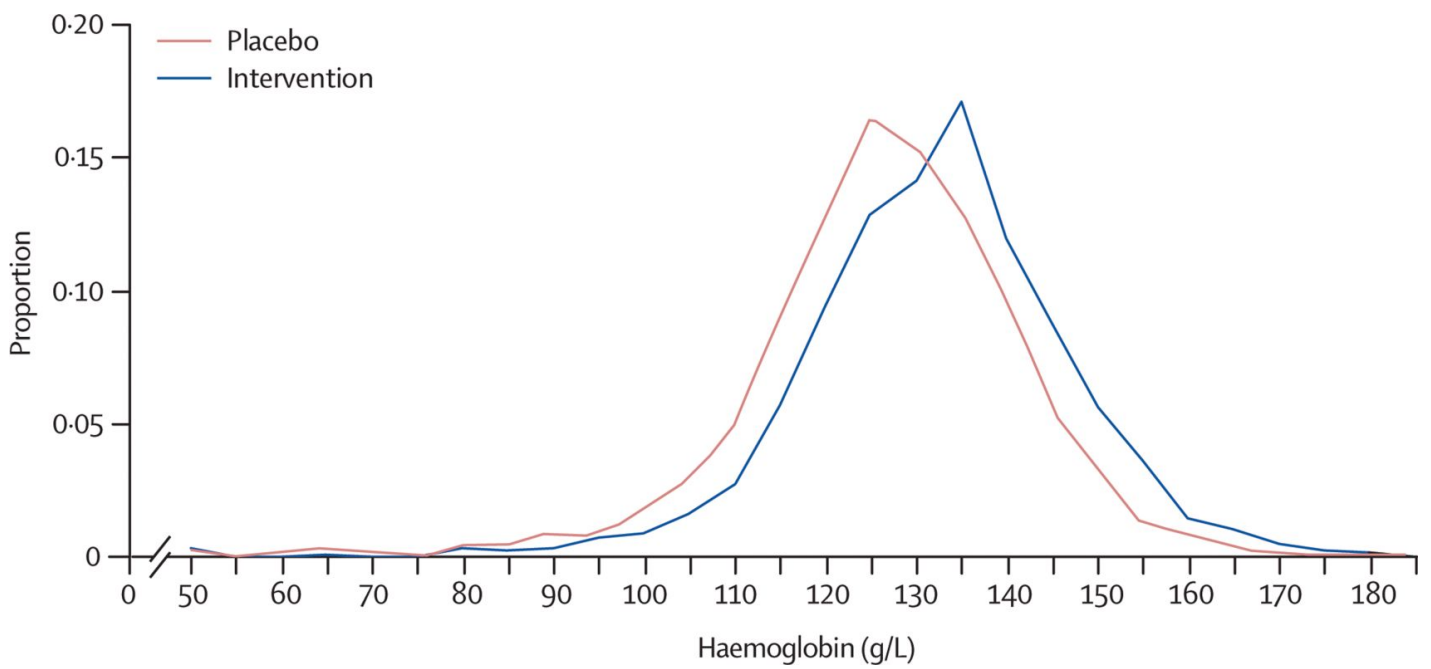

Figure 2.

Distribution of haemoglobin concentrations among children, according to treatment (intentionto-treat population)

Individual-level data are presented; distribution does not take into account the clustering of children within schools. 
Table 1

Characteristics of schoolchildren included in analyses of health outcomes*

\begin{tabular}{|c|c|c|c|c|}
\hline & \multicolumn{2}{|c|}{ Intention-to-treat population } & \multicolumn{2}{|c|}{ Per-protocol population } \\
\hline & Placebo & IPT & Placebo & IPT \\
\hline $\begin{array}{l}\text { Number of children included in } \\
\text { analysis }\end{array}$ & 2305 & 2611 & 1394 & 1070 \\
\hline Mean age (years) & $11 \cdot 23(3 \cdot 09)$ & $11 \cdot 24(3 \cdot 05)$ & $11 \cdot 51(2 \cdot 92)$ & $11 \cdot 53(2 \cdot 85)$ \\
\hline Sex (male) & $1209 / 2305(52 \%)$ & $1405 / 2611(54 \%)$ & $708 / 1394(51 \%)$ & $559 / 1070(52 \%)$ \\
\hline $\begin{array}{l}\text { History of residence in a non- } \\
\text { malarious area }\end{array}$ & $190 / 1952(10 \%)$ & $167 / 2221(8 \%)$ & $124 / 1239(10 \%)$ & $82 / 974(8 \%)$ \\
\hline Reported use of bednet by child & $561 / 1952(29 \%)$ & $495 / 2215(22 \%)$ & $346 / 1239(28 \%)$ & $211 / 970(22 \%)$ \\
\hline Household ownership of bicycle & $1434 / 1944(74 \%)$ & $1616 / 2222(73 \%)$ & $890 / 1232(72 \%)$ & $698 / 971(72 \%)$ \\
\hline \multicolumn{5}{|l|}{ House structure } \\
\hline Traditional & $654 / 1957(33 \%)$ & $745 / 2231(33 \%)$ & $406 / 1243(33 \%)$ & $321 / 977(33 \%)$ \\
\hline Semi-permanent & $831 / 1957(42 \%)$ & $874 / 2231(39 \%)$ & $529 / 1243(43 \%)$ & $386 / 977(40 \%)$ \\
\hline Permanent & $472 / 1957(24 \%)$ & $612 / 2231(27 \%)$ & $308 / 1243(25 \%)$ & $270 / 977(28 \%)$ \\
\hline \multicolumn{5}{|l|}{ Lighting } \\
\hline Tin lamp only & $1325 / 1956(68 \%)$ & $1400 / 2231(63 \%)$ & $839 / 1242(68 \%)$ & $624 / 976(64 \%)$ \\
\hline Hurricane lamp & $577 / 1956(29 \%)$ & $747 / 2231(33 \%)$ & $369 / 1242(30 \%)$ & $308 / 976(32 \%)$ \\
\hline Electricity/other & $54 / 1956(3 \%)$ & $84 / 2231(4 \%)$ & $34 / 1242(3 \%)$ & $44 / 976(5 \%)$ \\
\hline \multicolumn{5}{|l|}{ Family status } \\
\hline Lives with guardian & $421 / 1957(22 \%)$ & $437 / 2234(20 \%)$ & $260 / 1243(21 \%)$ & $217 / 977(22 \%)$ \\
\hline Lives with one parent & $371 / 1957(19 \%)$ & $421 / 2234(19 \%)$ & $231 / 1243(19 \%)$ & $159 / 977(16 \%)$ \\
\hline Lives with both parents & $1165 / 1957(60 \%)$ & $1369 / 2234(61 \%)$ & $752 / 1243(60 \%)$ & $601 / 977(62 \%)$ \\
\hline \multicolumn{5}{|l|}{ Parental education ${ }^{t^{1}}$} \\
\hline No education & $46 / 657(7 \%)$ & $59 / 711(8 \%)$ & $30 / 449(7 \%)$ & $32 / 346(9 \%)$ \\
\hline Primary education only & $341 / 657(52 \%)$ & $359 / 711(50 \%)$ & $236 / 449(53 \%)$ & $171 / 346(49 \%)$ \\
\hline Secondary education & $236 / 657(36 \%)$ & $253 / 711(36 \%)$ & $163 / 449(36 \%)$ & $121 / 346(35 \%)$ \\
\hline Higher education & $34 / 657(5 \%)$ & $40 / 711(6 \%)$ & $20 / 449(4 \%)$ & $22 / 346(6 \%)$ \\
\hline \multicolumn{5}{|l|}{ Nutritional status at baseline $e^{\dagger t}$} \\
\hline Weight-for-age $Z$ score & $-1.62(1.05)$ & $-1 \cdot 60(1 \cdot 11)$ & $-1.65(1.03)$ & $-1 \cdot 54(1.08)$ \\
\hline Height-for-age $Z$ score & $-1.68(1.02)$ & $-1.68(1.12)$ & $-1.67(1.02)$ & $-1.63(1 \cdot 10)$ \\
\hline \multicolumn{5}{|l|}{ Helminth infection at follow-up ${ }^{\S}$} \\
\hline Hookworm & $74 / 598(12 \%)$ & $82 / 612(13 \%)$ & $47 / 396(12 \%)$ & $34 / 272(13 \%)$ \\
\hline Ascaris lumbricoides & $28 / 598(5 \%)$ & $32 / 612(5 \%)$ & $15 / 396(4 \%)$ & $9 / 272(3 \%)$ \\
\hline Trichuris trichiura & $32 / 598(5 \%)$ & $52 / 612(8 \%)$ & $18 / 396(5 \%)$ & $23 / 272(8 \%)$ \\
\hline Schistosoma mansoni & $59 / 598(10 \%)$ & $32 / 612(5 \%)$ & $29 / 396(7 \%)$ & $15 / 272(6 \%)$ \\
\hline \multicolumn{5}{|l|}{ Study endpoints at baseline ${ }^{\dagger}$} \\
\hline Number of children examined & 1149 & 1330 & 748 & 637 \\
\hline$P$ falciparum prevalence & $465 / 1113(42 \%)$ & $524 / 1284(41 \%)$ & $278 / 728(38 \%)$ & $243 / 612(40 \%)$ \\
\hline $\begin{array}{l}P \text { falciparum intensity per } \mu \mathrm{L} \\
\text { among slide-positive: } \\
\text { geometric mean }\end{array}$ & $1028 \cdot 85(1 \cdot 30)$ & $988 \cdot 88(1 \cdot 18)$ & $923 \cdot 15(1 \cdot 26)$ & $961 \cdot 23(1 \cdot 14)$ \\
\hline Anaemia prevalence & $254 / 1145(22 \%)$ & $246 / 1326(19 \%)$ & $155 / 745(21 \%)$ & $104 / 636(16 \%)$ \\
\hline $\begin{array}{l}\text { Mean haemoglobin } \\
\text { concentration }(\mathrm{g} / \mathrm{L})\end{array}$ & $119 \cdot 50(15 \cdot 54)$ & $121.42(14 \cdot 47)$ & $119 \cdot 78(15 \cdot 27)$ & $122 \cdot 19(14 \cdot 13)$ \\
\hline
\end{tabular}

Data are mean $(\mathrm{SD})$ or $\mathrm{n} / \mathrm{N}(\%)$ unless specified otherwise.

* Data obtained at follow-up for all classes (5-18 years), apart from where indicated.

Measured at baseline among children who were enrolled in classes 5 and 6; also includes data for children in all classes in a randomly selected subset of 12 schools.

${ }^{\ddagger}$

hropometric indices calculated on the basis of the 2000 Centers for Disease Control and Prevention growth charts. Weight-for-height standards were only available for children up to $121 \mathrm{~cm}$ in height and thus not calculated. Measured at baseline (ITT: 1141 placebo, 1321 IPT; PP: 744 placebo, 633 IPT).

Helminth infection was only measured among children enrolled in classes 5 and 6 at baseline. 
Table 2

Characteristics of schoolchildren included in analyses of education outcomes*

\begin{tabular}{|c|c|c|c|c|}
\hline & \multicolumn{2}{|c|}{ Intention-to-treat population } & \multicolumn{2}{|c|}{ Per-protocol population } \\
\hline & Placebo & IPT & Placebo & IPT \\
\hline $\begin{array}{l}\text { Number of children included in } \\
\text { analysis }\end{array}$ & 382 & 436 & 274 & 209 \\
\hline Mean age (years) & $13 \cdot 74(1 \cdot 17)$ & $13 \cdot 89(1 \cdot 19)$ & $13 \cdot 71(1 \cdot 18)$ & $13 \cdot 83(1 \cdot 17)$ \\
\hline Sex (male) & $196 / 382(51 \%)$ & $213 / 436(49 \%)$ & $134 / 274(49 \%)$ & $97 / 209(46 \%)$ \\
\hline $\begin{array}{l}\text { History of residence in a non-malarious } \\
\text { area }\end{array}$ & $40 / 381(10 \%)$ & $47 / 435(11 \%)$ & $26 / 273(10 \%)$ & $25 / 208(12 \%)$ \\
\hline Reported use of bednet by child & $73 / 380(19 \%)$ & $72 / 433(17 \%)$ & $51 / 272(19 \%)$ & $33 / 208(16 \%)$ \\
\hline Household ownership of bicycle & $257 / 380(68 \%)$ & $290 / 433(67 \%)$ & $183 / 272(67 \%)$ & $136 / 208(65 \%)$ \\
\hline \multicolumn{5}{|l|}{ House structure } \\
\hline Traditional & $132 / 382(35 \%)$ & $153 / 435(35 \%)$ & $98 / 274(36 \%)$ & $66 / 208(32 \%)$ \\
\hline Semi-permanent & $164 / 382(43 \%)$ & $151 / 435(35 \%)$ & $113 / 274(41 \%)$ & $74 / 208(36 \%)$ \\
\hline Permanent & $86 / 382(23 \%)$ & $131 / 435(30 \%)$ & $63 / 274(23 \%)$ & $68 / 208(33 \%)$ \\
\hline \multicolumn{5}{|l|}{ Lighting } \\
\hline Tin lamp only & $268 / 382(70 \%)$ & $267 / 435(61 \%)$ & $193 / 274(70 \%)$ & $125 / 208(60 \%)$ \\
\hline Hurricane lamp & $107 / 382(28 \%)$ & $152 / 435(35 \%)$ & $76 / 274(28 \%)$ & $72 / 208(35 \%)$ \\
\hline Electricity/other & $7 / 382(2 \%)$ & $16 / 435(4 \%)$ & $5 / 274(2 \%)$ & $11 / 208(5 \%)$ \\
\hline \multicolumn{5}{|l|}{ Family status } \\
\hline Lives with guardian & $89 / 382(23 \%)$ & $94 / 433(22 \%)$ & $60 / 274(22 \%)$ & $47 / 207(23 \%)$ \\
\hline Lives with one parent & $74 / 382(19 \%)$ & $93 / 433(21 \%)$ & $53 / 274(19 \%)$ & $39 / 207(19 \%)$ \\
\hline Lives with both parents & $219 / 382(57 \%)$ & $246 / 433(57 \%)$ & $161 / 274(59 \%)$ & $121 / 207(58 \%)$ \\
\hline \multicolumn{5}{|l|}{ Parental education ${ }^{\dagger}$} \\
\hline No education & $24 / 298(8 \%)$ & $31 / 315(10 \%)$ & $18 / 213(8 \%)$ & $16 / 144(11 \%)$ \\
\hline Primary education only & $139 / 298(47 \%)$ & $158 / 315(50 \%)$ & $93 / 213(44 \%)$ & $68 / 144(47 \%)$ \\
\hline Secondary education & $117 / 298(39 \%)$ & $111 / 315(35 \%)$ & $90 / 213(42 \%)$ & $51 / 144(35 \%)$ \\
\hline Higher education & $18 / 298(6 \%)$ & $15 / 315(5 \%)$ & $12 / 213(6 \%)$ & $9 / 144(6 \%)$ \\
\hline \multicolumn{5}{|l|}{ Nutritional status at baseline $e^{\dagger+}$} \\
\hline Weight-for-age $Z$ score & $-1.75(1.07)$ & $-1 \cdot 65(1.09)$ & $-1.73(1.07)$ & $-1.58(1.07)$ \\
\hline Height-for-age $Z$ score & $-1.67(0.98)$ & $-1.63(1.03)$ & $-1.65(0.99)$ & $-1.62(1.03)$ \\
\hline \multicolumn{5}{|l|}{ Helminth infection at follow-up } \\
\hline Hookworm & $44 / 357(12 \%)$ & $45 / 387(12 \%)$ & $29 / 255(11 \%)$ & $23 / 192(12 \%)$ \\
\hline Ascaris lumbricoides & $11 / 357(3 \%)$ & $21 / 387(5 \%)$ & $6 / 255(2 \%)$ & $7 / 192(4 \%)$ \\
\hline Trichuris trichiura & $15 / 357(4 \%)$ & $36 / 387(9 \%)$ & $9 / 255(4 \%)$ & $17 / 192(9 \%)$ \\
\hline Schistosoma mansoni & $28 / 357(8 \%)$ & $18 / 387(5 \%)$ & $14 / 255(5 \%)$ & $10 / 192(5 \%)$ \\
\hline \multicolumn{5}{|l|}{ Study endpoints at baseline ${ }^{\dagger}$} \\
\hline Number of children examined & 361 & 416 & 261 & 201 \\
\hline$P$ falciparum prevalence & $130 / 349(37 \%)$ & $139 / 406(34 \%)$ & $87 / 254(34 \%)$ & $72 / 195(37 \%)$ \\
\hline $\begin{array}{l}P \text { falciparum intensity per } \mu \mathrm{L} \text { in } \\
\text { slide-positive: geometric mean }\end{array}$ & $802 \cdot 32(1 \cdot 19)$ & $733 \cdot 21(1 \cdot 14)$ & $805.45(1.11)$ & $725 \cdot 65(1 \cdot 12)$ \\
\hline Anaemia prevalence & $55 / 359(15 \%)$ & $44 / 416(11 \%)$ & $34 / 260(13 \%)$ & $24 / 201(12 \%)$ \\
\hline $\begin{array}{l}\text { Mean haemoglobin concentration } \\
(\mathrm{g} / \mathrm{L})\end{array}$ & $122 \cdot 92(15 \cdot 26)$ & $124 \cdot 81(13 \cdot 92)$ & $123 \cdot 26(14 \cdot 57)$ & $124.90(14 \cdot 06)$ \\
\hline $\begin{array}{l}\text { Mean score in counting sounds } \\
\text { test }^{\S}\end{array}$ & $11 \cdot 19(3 \cdot 02)$ & $11 \cdot 25(3 \cdot 04)$ & $11 \cdot 12(2 \cdot 99)$ & $11 \cdot 08(3 \cdot 22)$ \\
\hline $\begin{array}{l}\text { Mean score in code transmission } \\
\text { test }^{\S}\end{array}$ & $13 \cdot 03(4 \cdot 99)$ & $13 \cdot 31(4 \cdot 99)$ & $13 \cdot 11(4 \cdot 74)$ & $13 \cdot 47(5 \cdot 00)$ \\
\hline
\end{tabular}

Data are mean (SD) or $\mathrm{n} / \mathrm{N}(\%)$ unless specified otherwise.

* Data obtained at follow-up for education cohort recruited from classes 5 and 6 (11-16 years), except where indicated.

${ }^{\dagger}$ Measured at baseline.

Fnthropometric indices calculated on the basis of the 2000 Centers for Disease Control and Prevention growth charts. Weight-for-height standards were only available for children up to $121 \mathrm{~cm}$ in height and thus not calculated. Measured at baseline (ITT: 359 placebo, 415 IPT; PP: 260 placebo, 200 IPT).

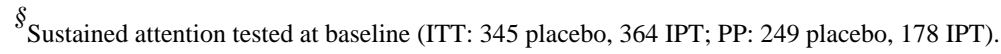


Table 3

Data on school level characteristics* for schoolchildren included in analyses of education outcomes

\begin{tabular}{|c|c|c|}
\hline & Placebo & IPT \\
\hline \multicolumn{3}{|l|}{ School exam performance in previous 3 years ${ }^{\dagger \dagger}$} \\
\hline Lowest tertile (stratum 1 ) & $219 \cdot 55(219 \cdot 48-220 \cdot 25)$ & $205 \cdot 34(204 \cdot 34-217 \cdot 76)$ \\
\hline Middle tertile (stratum 2) & $246 \cdot 38(245 \cdot 96-249 \cdot 23)$ & $233.47(232 \cdot 43-235 \cdot 05)$ \\
\hline Upper tertile (stratum 3 ) & $267 \cdot 81(266 \cdot 95-272 \cdot 32)$ & $291.08(277 \cdot 63-296 \cdot 91)$ \\
\hline \multicolumn{3}{|l|}{ Mean number of children enrolled per school (classes 0-7) ${ }^{\dagger}$} \\
\hline School performance stratum 1 & $156 \cdot 0(44 \cdot 20)$ & $144 \cdot 2(50 \cdot 25)$ \\
\hline School performance stratum 2 & $214 \cdot 6(50 \cdot 86)$ & $250 \cdot 8(33 \cdot 80)$ \\
\hline School performance stratum 3 & $298 \cdot 8(161 \cdot 06)$ & $338 \cdot 2(124 \cdot 12)$ \\
\hline \multicolumn{3}{|l|}{ Quality of social science teaching during final term of intervention } \\
\hline Absent for $>1$ day & $11(73 \%)$ & $10(67 \%)$ \\
\hline Number of days absent & 3 days $(2-8)$ & $3 \cdot 5$ days $(2-5)$ \\
\hline Proportion of work completed and marked & $0 \cdot 16(0 \cdot 15)$ & $0 \cdot 14(0 \cdot 17)$ \\
\hline Progression: number of lessons per week & $4 \cdot 25(1 \cdot 83)$ & $6 \cdot 33(3 \cdot 90)$ \\
\hline Lesson plans: number of lesson plans per week & $3 \cdot 53(2 \cdot 83)$ & $3 \cdot 67(3 \cdot 29)$ \\
\hline \multicolumn{3}{|l|}{ Number of teaching aids in use } \\
\hline None & $4(27 \%)$ & $5(33 \%)$ \\
\hline One & $1(7 \%)$ & $2(13 \%)$ \\
\hline Two or more & $10(67 \%)$ & $8(53 \%)$ \\
\hline
\end{tabular}

Data are mean (SD), median (IQR), or n $(\%)$. Intention-to-treat and per-protocol populations drawn from same set of 30 study schools (15 placebo, 15 IPT).

${ }^{\dagger}$ Five schools per strata in each treatment arm.

Median (IQR) of the mean pass rate in national primary school leaving exams (KCPE) during 3 years before intervention. 
Table 4

Effect of IPT on health outcomes: anaemia, haemoglobin, and $P$ falciparum parasitaemia

\begin{tabular}{|c|c|c|c|c|c|c|}
\hline & \multicolumn{2}{|l|}{ Placebo } & \multicolumn{2}{|l|}{ IPT } & \multirow[t]{2}{*}{ p value } & \multirow{2}{*}{$\begin{array}{l}\text { Risk ratio/ } \\
\text { mean } \\
\text { difference* } \\
(95 \% \mathrm{CI})\end{array}$} \\
\hline & Number of children & Outcome & Number of children & Outcome & & \\
\hline \multicolumn{7}{|c|}{ Intention-to-treat analysis ${ }^{\dagger}$} \\
\hline $\begin{array}{l}\text { Prevalence of anaemia } \\
\text { Crude }\end{array}$ & 2302 & $12.6 \%$ & 2604 & $6.3 \%$ & $\mathrm{p}=0.041$ & $\begin{array}{l}0.50(0 \cdot 26- \\
0.97)\end{array}$ \\
\hline $\begin{array}{l}\text { (Range between schools; } \\
\mathrm{k}=0 \cdot 44)\end{array}$ & & $\begin{array}{l}(5 \cdot 7- \\
40 \cdot 3 \%)\end{array}$ & & $\begin{array}{l}(0.7- \\
12.5 \%)\end{array}$ & & \\
\hline $\begin{array}{l}\text { Observed/expected: } \\
\text { adjusted for strata }{ }^{\S}\end{array}$ & 2302 & $1 \cdot 347$ & 2604 & $0 \cdot 689$ & $\mathrm{p}=0.034$ & $\begin{array}{l}0.51(0.28- \\
0.95)\end{array}$ \\
\hline $\begin{array}{l}\text { Observed/ } \\
\text { expected: fully adjusted }{ }^{I l} \\
\text { Mean haemoglobin concer }\end{array}$ & 2292 & $1 \cdot 326$ & 2599 & 0.689 & $\mathrm{p}=0.028$ & $\begin{array}{l}0.52(0 \cdot 29- \\
0.92)\end{array}$ \\
\hline Crude ${ }^{\ddagger}$ & 2302 & $124 \cdot 5$ & 2604 & $130 \cdot 1$ & $\mathrm{p}=0.002$ & $\begin{array}{l}5 \cdot 62(2 \cdot 19- \\
9 \cdot 05)\end{array}$ \\
\hline $\begin{array}{l}\text { (Range between schools; } \\
\mathrm{k}=0.03 \text { ) }\end{array}$ & & $\begin{array}{l}(111 \cdot 9- \\
128 \cdot 3)\end{array}$ & & $\begin{array}{l}(123 \cdot 7- \\
138 \cdot 4)\end{array}$ & & \\
\hline $\begin{array}{l}\text { Observed-expected: } \\
\text { adjusted for strata }\end{array}$ & 2302 & $-2 \cdot 94$ & 2604 & $2 \cdot 68$ & $\mathrm{p}=0.002$ & $\begin{array}{l}5 \cdot 62(2 \cdot 19- \\
9 \cdot 05)\end{array}$ \\
\hline $\begin{array}{l}\text { Observed- } \\
\text { expected: fully adjusted } q \\
\text { Prevalence of } P \text { falciparun }\end{array}$ & $\begin{array}{l}2292 \\
\text { ction }\end{array}$ & $-2 \cdot 14$ & 2599 & $2 \cdot 88$ & $\mathrm{p}=0.005$ & $\begin{array}{l}5 \cdot 01(1 \cdot 62- \\
8 \cdot 41)\end{array}$ \\
\hline Crude & 2294 & $39 \cdot 7 \%$ & 2584 & $4.6 \%$ & $\mathrm{p}<0.0001$ & $\begin{array}{l}0.12(0.05- \\
0.27)\end{array}$ \\
\hline $\begin{array}{l}\text { (Range between schools; } \\
\mathrm{k}=0 \cdot 14)\end{array}$ & & $\begin{array}{l}(26 \cdot 2- \\
58 \cdot 1 \%)\end{array}$ & & $\begin{array}{l}(0 \cdot 8- \\
14 \cdot 1 \%)\end{array}$ & & \\
\hline $\begin{array}{l}\text { Observed/expected: } \\
\text { adjusted for strata }\end{array}$ & 2294 & 1.949 & 2584 & $0 \cdot 226$ & $\mathrm{p}<0 \cdot 0001$ & $\begin{array}{l}0 \cdot 12(0 \cdot 05- \\
0 \cdot 27)\end{array}$ \\
\hline $\begin{array}{l}\text { Observed/ } \\
\text { expected: fully adjusted/l }\end{array}$ & 1938 & 2.532 & 2182 & 0.286 & $\mathrm{p}=0 \cdot 0002$ & $\begin{array}{l}0.11(0 \cdot 05- \\
0.27)\end{array}$ \\
\hline \multicolumn{7}{|c|}{ Intensity of $P$ falciparum infection (per $\mu \mathrm{L}$ ) ${ }^{* *}$} \\
\hline Crude & 890 & $1282 \cdot 5$ & 104 & $2118 \cdot 8$ & $\mathrm{p}=0.255$ & $\begin{array}{l}1 \cdot 65(0 \cdot 68- \\
4 \cdot 01)\end{array}$ \\
\hline $\begin{array}{l}\text { Observed-expected: } \\
\text { adjusted for strata }^{\S}\end{array}$ & 890 & $-0 \cdot 254$ & 104 & 0.248 & $\mathrm{p}=0.255$ & $\begin{array}{l}1 \cdot 65(0 \cdot 68- \\
4 \cdot 01)\end{array}$ \\
\hline $\begin{array}{l}\text { Observed- } \\
\text { expected: fully adjusted } \\
\text { Per-protocol analysis } \\
{ }^{\dagger \dagger} \\
\text { Prevalence of anaemia }\end{array}$ & 699 & $0 \cdot 315$ & 74 & 1.013 & $\mathrm{p}=0 \cdot 108$ & $\begin{array}{l}2 \cdot 01(0 \cdot 85- \\
4 \cdot 77)\end{array}$ \\
\hline 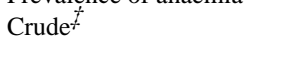 & 1392 & $12 \cdot 8 \%$ & 1070 & $5.7 \%$ & $\mathrm{p}=0.027$ & $\begin{array}{l}0.44(0.22- \\
0.90)\end{array}$ \\
\hline $\begin{array}{l}\text { (Range between schools; } \\
\mathrm{k}=0.44)\end{array}$ & & $\begin{array}{l}(5 \cdot 5- \\
36 \cdot 4 \%)\end{array}$ & & $\begin{array}{l}(0- \\
17.9 \%)\end{array}$ & & \\
\hline $\begin{array}{l}\text { Observed/expected: } \\
\text { adjusted for strata }\end{array}$ & 1392 & $1 \cdot 369$ & 1070 & $0 \cdot 624$ & $\mathrm{p}=0.027$ & $\begin{array}{l}0.46(0 \cdot 23- \\
0.91)\end{array}$ \\
\hline $\begin{array}{l}\text { Observed/ } \\
\text { expected: fully adjusted } I l \\
\text { Mean haemoglobin concer }\end{array}$ & 1387 & $1 \cdot 351$ & 1068 & 0.633 & $\mathrm{p}=0 \cdot 025$ & $\begin{array}{l}0.47(0.24- \\
0.90)\end{array}$ \\
\hline Crude & 1392 & $124 \cdot 8$ & 1070 & $130 \cdot 7$ & $\mathrm{p}=0 \cdot 0010$ & $\begin{array}{l}5 \cdot 99(2 \cdot 70- \\
9 \cdot 28)\end{array}$ \\
\hline $\begin{array}{l}\text { (Range between schools; } \\
\mathrm{k}=0.03)\end{array}$ & & $\begin{array}{l}(114.9- \\
128 \cdot 5)\end{array}$ & & $\begin{array}{l}(123 \cdot 2- \\
139 \cdot 2)\end{array}$ & & \\
\hline $\begin{array}{l}\text { Observed-expected: } \\
\text { adjusted for strata }\end{array}$ & 1392 & $-2 \cdot 90$ & 1070 & 3.09 & $\mathrm{p}=0 \cdot 0010$ & $\begin{array}{l}5.99(2.70- \\
9 \cdot 28)\end{array}$ \\
\hline $\begin{array}{l}\text { Observed- } \\
\text { expected: fully adjusted } \mathscr{I} \\
\text { Prevalence of } P \text { falciparun }\end{array}$ & 1387 & $-2 \cdot 32$ & 1068 & $3 \cdot 17$ & $\mathrm{p}=0.0023$ & $\begin{array}{l}5.49(2 \cdot 16- \\
8 \cdot 81)\end{array}$ \\
\hline Crude ${ }^{\ddagger}$ & 1386 & $39.3 \%$ & 1059 & $3.7 \%$ & $\mathrm{p}=0.0002$ & $\begin{array}{l}0.10(0.03- \\
0.28)\end{array}$ \\
\hline $\begin{array}{l}\text { (Range between schools; } \\
\mathrm{k}=0.18)\end{array}$ & & $\begin{array}{l}(23.0- \\
59 \cdot 4 \%)\end{array}$ & & $\begin{array}{l}(0- \\
13 \cdot 3 \%)\end{array}$ & & \\
\hline $\begin{array}{l}\text { Observed/expected: } \\
\text { adjusted for strata } \\
\$\end{array}$ & 1386 & 1.709 & 1059 & $0 \cdot 166$ & $\mathrm{p}=0.0003$ & $\begin{array}{l}0 \cdot 10(0 \cdot 03- \\
0 \cdot 30)\end{array}$ \\
\hline $\begin{array}{l}\text { Observed/ } \\
\text { expected: fully adjusted } /\end{array}$ & 1228 & 2.064 & 957 & $0 \cdot 189$ & $\mathrm{p}=0.0003$ & $\begin{array}{l}0.09(0.03- \\
0.29)\end{array}$ \\
\hline
\end{tabular}




\begin{tabular}{|c|c|c|c|c|c|c|}
\hline & \multicolumn{2}{|l|}{ Placebo } & \multicolumn{2}{|l|}{ IPT } & \multirow[t]{2}{*}{ p value } & \multirow{2}{*}{$\begin{array}{l}\text { Risk ratio/ } \\
\text { mean } \\
\text { difference } \\
(95 \% \mathrm{CI})\end{array}$} \\
\hline & Number of children & Outcome & Number of children & Outcome & & \\
\hline Crude & 530 & $1110 \cdot 5$ & 38 & $1262 \cdot 2$ & $\mathrm{p}=0.799$ & $\begin{array}{l}1 \cdot 14(0 \cdot 41- \\
3 \cdot 18)\end{array}$ \\
\hline $\begin{array}{l}\text { Observed-expected: } \\
\text { adjusted for strata }\end{array}$ & 530 & $-0 \cdot 251$ & 38 & $-0 \cdot 123$ & $\mathrm{p}=0.799$ & $\begin{array}{l}1 \cdot 14(0 \cdot 41- \\
3 \cdot 18)\end{array}$ \\
\hline $\begin{array}{l}\text { Observed- } \\
\text { expected: fully adjusted }\end{array}$ & 444 & $0 \cdot 101$ & 32 & $0 \cdot 210$ & $\mathrm{p}=0.829$ & $\begin{array}{l}1 \cdot 12(0 \cdot 40- \\
3 \cdot 12)\end{array}$ \\
\hline
\end{tabular}

Placebo and IPT intervention arms both contained 15 schools.

Risk ratios are presented for binary outcomes (anaemia and $P$ falciparum occurrence), mean differences are presented for haemoglobin concentrations. Ratio of geometric means are presented for $P$ falciparum intensity among those infected.

$+$

Intention-to-treat analysis: placebo $n=2305$, range 64-382 children per school; IPT n=2611, range 70-341 children per school.

$\neq$

${ }^{\ddagger}$ Crude estimates account for the cluster-randomised trial design. Prevalence was calculated for each school, and the percentage shown represents the mean of these cluster-specific prevalence values.

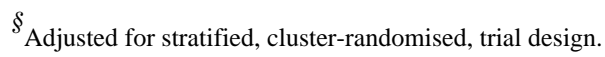

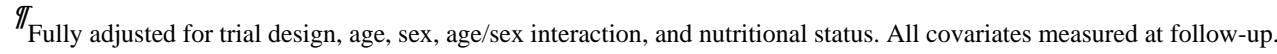

//Fully adjusted for trial design, age, sex, age/sex interaction, bednet use, and migration history. All covariates measured at follow-up.

** Geometric mean parasite density calculated in parasite-positive children only.

${ }^{+\dagger}$ Per-protocol analysis: placebo $n=1394$, range $33-171$ children per school. IPT $n=1070$, range $24-165$ children per school. 
Table 5

Effect of IPT on cognition: attention in class

\begin{tabular}{|c|c|c|c|c|c|c|}
\hline & \multicolumn{2}{|l|}{ Placebo } & \multicolumn{2}{|l|}{ IPT } & \multirow[t]{2}{*}{ p value } & \multirow{2}{*}{$\begin{array}{l}\text { Difference in } \\
\text { means }(95 \% \\
\text { CI) }\end{array}$} \\
\hline & $\begin{array}{l}\text { Number } \\
\text { of } \\
\text { children } \\
\text { tested }\end{array}$ & Mean score & $\begin{array}{l}\text { Number } \\
\text { of } \\
\text { children } \\
\text { tested }\end{array}$ & Mean score & & \\
\hline \multicolumn{7}{|c|}{ Intention-to-treat analysis } \\
\hline \multicolumn{7}{|c|}{ Counting sounds (maximum score $20{ }^{*}$} \\
\hline Crude $^{f}$ & 378 & $15 \cdot 41$ & 433 & $16 \cdot 01$ & $\mathrm{p}=0.048$ & $\begin{array}{l}0.60(0.01 \text { to } \\
1 \cdot 19)\end{array}$ \\
\hline $\begin{array}{l}\text { (Range between schools; } \\
\mathrm{k}=0.03 \text { ) }\end{array}$ & & $\begin{array}{l}(13 \cdot 47- \\
16 \cdot 40)\end{array}$ & & $\begin{array}{l}(14 \cdot 63- \\
17 \cdot 30)\end{array}$ & & \\
\hline $\begin{array}{l}\text { Observed-expected: } \\
\text { adjusted for strata }\end{array}$ & 378 & $-0 \cdot 329$ & 433 & $0 \cdot 266$ & $\mathrm{p}=0.048$ & $\begin{array}{l}0.60(0.01 \text { to } \\
1 \cdot 19)\end{array}$ \\
\hline $\begin{array}{l}\text { Observed- } \\
\text { expected: fully adjusted }\end{array}$ & 328 & $1 \cdot 405$ & 351 & $3 \cdot 208$ & $\mathrm{p}=0.030$ & $\begin{array}{l}1.80(0 \cdot 19 \text { to } \\
3 \cdot 41)\end{array}$ \\
\hline \multicolumn{7}{|c|}{ Code transmission (maximum score 40 ) } \\
\hline Crude $^{\dagger}$ & 368 & $23 \cdot 28$ & 423 & $27 \cdot 20$ & $\mathrm{p}=0.019$ & $\begin{array}{l}3.92(0.70 \text { to } \\
7 \cdot 14)\end{array}$ \\
\hline $\begin{array}{l}\text { (Range between schools; } \\
\mathrm{k}=0 \cdot 15 \text { ) }\end{array}$ & & $\begin{array}{l}(16 \cdot 87- \\
31 \cdot 00)\end{array}$ & & $\begin{array}{l}(19 \cdot 50- \\
33 \cdot 62)\end{array}$ & & \\
\hline $\begin{array}{l}\text { Observed-expected: } \\
\text { adjusted for strata }\end{array}$ & 368 & $-1 \cdot 862$ & 423 & $2 \cdot 058$ & $\mathrm{p}=0.019$ & $\begin{array}{l}3.92(0 \cdot 70 \text { to } \\
7 \cdot 14)\end{array}$ \\
\hline $\begin{array}{l}\text { Observed- } \\
\text { expected: fully adjusted } \\
\S\end{array}$ & 323 & 0.572 & 342 & $6 \cdot 624$ & $\mathrm{p}=0.0007$ & $\begin{array}{l}6 \cdot 05(2 \cdot 83 \text { to } \\
9 \cdot 27)\end{array}$ \\
\hline \multicolumn{7}{|c|}{ Teacher-rated score for inattentive or hyperactive-compulsive behaviours (maximum score 38) $/ /$} \\
\hline Crude $^{\dagger}$ & 137 & $11 \cdot 67$ & 126 & $10 \cdot 90$ & $\mathrm{p}=0.543$ & $\begin{array}{l}-0.77(-3.36 \\
\text { to } 1.82)\end{array}$ \\
\hline $\begin{array}{l}\text { Observed-expected: } \\
\text { adjusted for strata }\end{array}$ & 137 & $0 \cdot 170$ & 126 & -0.729 & $\mathrm{p}=0.481$ & $\begin{array}{l}-0.90(-3.49 \\
\text { to } 1.69)\end{array}$ \\
\hline $\begin{array}{l}\text { Observed- } \\
\text { expected: fully adjusted }\end{array}$ & 134 & 0.204 & 120 & $0 \cdot 057$ & $\mathrm{p}=0.910$ & $\begin{array}{l}-0 \cdot 15(-2 \cdot 81 \\
\text { to } 2 \cdot 52)\end{array}$ \\
\hline \multicolumn{7}{|c|}{ Per-protocol analysis $\quad *$} \\
\hline \multicolumn{7}{|c|}{ Counting sounds (maximum score 20$)^{*}$} \\
\hline Crude $^{f}$ & 272 & $15 \cdot 48$ & 209 & $16 \cdot 14$ & $\mathrm{p}=0.097$ & $\begin{array}{l}0.66(-0.13 \text { to } \\
1.45)\end{array}$ \\
\hline $\begin{array}{l}\text { (Range between schools; } \\
\mathrm{k}=0.02 \text { ) }\end{array}$ & & $\begin{array}{l}(13 \cdot 14- \\
16 \cdot 33)\end{array}$ & & $\begin{array}{l}(13 \cdot 00- \\
17 \cdot 70)\end{array}$ & & \\
\hline $\begin{array}{l}\text { Observed-expected: } \\
\text { adjusted for strata }\end{array}$ & 272 & $-0 \cdot 255$ & 209 & $0 \cdot 407$ & $\mathrm{p}=0.097$ & $\begin{array}{l}0.66(-0.13 \text { to } \\
1.45)\end{array}$ \\
\hline $\begin{array}{l}\text { Observed- } \\
\text { expected: fully adjusted } \\
\S\end{array}$ & 238 & 1.403 & 173 & 3.530 & $\mathrm{p}=0.068$ & $\begin{array}{l}2 \cdot 13(-0 \cdot 17 \text { to } \\
4 \cdot 42)\end{array}$ \\
\hline \multicolumn{7}{|c|}{ Code transmission (maximum score 40 ) } \\
\hline Crude $^{\dagger}$ & 264 & $23 \cdot 32$ & 205 & $27 \cdot 72$ & $\mathrm{p}=0.013$ & $\begin{array}{l}4.40(1.01 \text { to } \\
7.80)\end{array}$ \\
\hline $\begin{array}{l}\text { (Range between schools; } \\
\mathrm{k}=0 \cdot 16 \text { ) }\end{array}$ & & $\begin{array}{l}(15 \cdot 60- \\
31 \cdot 20)\end{array}$ & & $\begin{array}{l}(17 \cdot 86- \\
33 \cdot 40)\end{array}$ & & \\
\hline $\begin{array}{l}\text { Observed-expected: } \\
\text { adjusted for strata }\end{array}$ & 264 & $-2 \cdot 155$ & 205 & $2 \cdot 249$ & $\mathrm{p}=0.013$ & $\begin{array}{l}4.40(1 \cdot 01 \text { to } \\
7 \cdot 80)\end{array}$ \\
\hline $\begin{array}{l}\text { Observed- } \\
\text { expected: fully adjusted } \\
\S\end{array}$ & 234 & 0.471 & 169 & $7 \cdot 214$ & $\mathrm{p}=0.0016$ & $\begin{array}{l}6.74(2.84 \text { to } \\
10 \cdot 65)\end{array}$ \\
\hline \multicolumn{7}{|c|}{ Teacher-rated score for inattentive or hyperactive-compulsive behaviours (maximum score 38 ) $/ /$} \\
\hline Crude $^{\dagger}$ & 106 & $11 \cdot 58$ & 68 & $10 \cdot 62$ & $\mathrm{p}=0.537$ & $\begin{array}{l}-0 \cdot 96(-4 \cdot 11 \\
\text { to } 2 \cdot 19)\end{array}$ \\
\hline $\begin{array}{l}\text { Observed-expected: } \\
\text { adjusted for strata }\end{array}$ & 106 & $-0 \cdot 135$ & 68 & -1.499 & $\mathrm{p}=0.381$ & $\begin{array}{l}-1 \cdot 36(-4.52 \\
\text { to } 1 \cdot 79)\end{array}$ \\
\hline $\begin{array}{l}\text { Observed- } \\
\text { expected: fully adjusted }\end{array}$ & 105 & $-0 \cdot 019$ & 67 & $-0 \cdot 457$ & $\mathrm{p}=0 \cdot 818$ & $\begin{array}{l}-0.44(-4.33 \\
\text { to } 3.45)\end{array}$ \\
\hline
\end{tabular}

Placebo and IPT intervention arms both contained 15 schools.

*

Test included 20 counting sounds tasks, with up to 30 sounds per task. The total score was the number of times the sounds were counted correctly.

${ }^{\dagger}$ Crude estimates account for the cluster-randomised trial design.

\#.jjusted for stratified, cluster-randomised, trial design. 


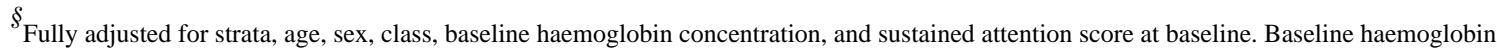
concentration and baseline sustained attention scores were not available for all children.

"Test included two tests, in which children were required to record the two or three numbers, respectively, that preceded the code. Each test comprised 20 sets of code transmission targets. The total score was the number of times the target digits were correctly identified.

"Data available for children in 14 schools in each treatment arm in per-protocol analysis; and for 14 schools in placebo arm in intention-to-treat analysis. $* *$

Fully adjusted for strata, age, sex, class, baseline haemoglobin concentrations. Baseline haemoglobin was not available for all children. Since attention function was only assessed post-treatment, no adjustments could be made for attention at baseline. 
Table 6

Effect of IPT on educational achievement

\begin{tabular}{|c|c|c|c|c|c|c|}
\hline & \multicolumn{2}{|l|}{ Placebo } & \multicolumn{2}{|l|}{ IPT } & \multirow[t]{2}{*}{ p value } & \multirow{2}{*}{$\begin{array}{l}\text { Difference in } \\
\text { means }(95 \% \\
\text { CI) }\end{array}$} \\
\hline & $\begin{array}{l}\text { Number } \\
\text { of } \\
\text { children } \\
\text { tested }\end{array}$ & Mean score & $\begin{array}{l}\text { Number } \\
\text { of } \\
\text { children } \\
\text { tested }\end{array}$ & Mean score & & \\
\hline \multicolumn{7}{|c|}{ Intention-to-treat analysis } \\
\hline \multicolumn{7}{|c|}{ Social science exam: standard 6 (maximum score 39$)^{*}$} \\
\hline Crude $^{\dagger}$ & 240 & $16 \cdot 20$ & 263 & $16 \cdot 27$ & $\mathrm{p}=0.951$ & $\begin{array}{l}0.07(-2.36 \text { to } \\
2 \cdot 50)\end{array}$ \\
\hline $\begin{array}{l}\text { Observed-expected: } \\
\text { adjusted for strata }\end{array}$ & 240 & $-0 \cdot 002$ & 263 & 0.071 & $\mathrm{p}=0.951$ & $\begin{array}{l}0.07(-2 \cdot 36 \text { to } \\
2 \cdot 50)\end{array}$ \\
\hline $\begin{array}{l}\text { Observed- } \\
\text { expected: fully adjusted }\end{array}$ & 200 & $1 \cdot 893$ & 250 & $1 \cdot 440$ & $\mathrm{p}=0.747$ & $\begin{array}{l}-0.45(-3.32 \\
\text { to } 2 \cdot 41)\end{array}$ \\
\hline \multicolumn{7}{|c|}{ Social science exam: standard 7 (maximum score 34$)^{* I I}$} \\
\hline Crude $^{\dagger}$ & 198 & $14 \cdot 78$ & 232 & $15 \cdot 60$ & $\mathrm{p}=0 \cdot 305$ & $\begin{array}{l}0 \cdot 83(-0 \cdot 80 \text { to } \\
2 \cdot 46)\end{array}$ \\
\hline $\begin{array}{l}\text { Observed-expected: } \\
\text { adjusted for strata }\end{array}$ & 198 & $-0 \cdot 399$ & 232 & $0 \cdot 380$ & $\mathrm{p}=0.333$ & $\begin{array}{l}0.78(-0 \cdot 85 \text { to } \\
2 \cdot 41)\end{array}$ \\
\hline $\begin{array}{l}\text { Observed- } \\
\text { expected: fully adjusted } \\
\S\end{array}$ & 137 & $3 \cdot 815$ & 195 & 3.964 & $\mathrm{p}=0.938$ & $\begin{array}{l}0.15(-3.75 \text { to } \\
4.05)\end{array}$ \\
\hline \multicolumn{7}{|c|}{ Per-protocol analysis } \\
\hline \multicolumn{7}{|c|}{ Social science exam: standard 6 (maximum score 39$)^{*}$} \\
\hline Crude $^{\dagger}$ & 167 & $16 \cdot 26$ & 119 & $16 \cdot 66$ & $\mathrm{p}=0.774$ & $\begin{array}{l}0.40(-2 \cdot 46 \text { to } \\
3 \cdot 26)\end{array}$ \\
\hline $\begin{array}{l}\text { Observed-expected: } \\
\text { adjusted for strata }\end{array}$ & 167 & $-0 \cdot 419$ & 119 & $-0 \cdot 017$ & $\mathrm{p}=0.774$ & $\begin{array}{l}0 \cdot 40(-2 \cdot 46 \text { to } \\
3 \cdot 26)\end{array}$ \\
\hline $\begin{array}{l}\text { Observed- } \\
\text { expected: fully adjusted } \S\end{array}$ & 144 & $1 \cdot 583$ & 116 & $1 \cdot 193$ & $\mathrm{p}=0.784$ & $\begin{array}{l}-0.39(-3.29 \\
\text { to } 2.51)\end{array}$ \\
\hline \multicolumn{7}{|c|}{ Social science exam: standard 7 (maximum score 34$)^{* \mathscr{I}}$} \\
\hline Crude $^{\dagger}$ & 146 & $14 \cdot 71$ & 120 & $15 \cdot 41$ & $\mathrm{p}=0 \cdot 362$ & $\begin{array}{l}0.71(-0.87 \text { to } \\
2 \cdot 28)\end{array}$ \\
\hline $\begin{array}{l}\text { Observed-expected: } \\
\text { adjusted for strata }\end{array}$ & 146 & $-0 \cdot 606$ & 120 & 0.018 & $\mathrm{p}=0.421$ & $\begin{array}{l}0.62(-0.95 \text { to } \\
2 \cdot 20)\end{array}$ \\
\hline $\begin{array}{l}\text { Observed- } \\
\text { expected: fully adjusted }\end{array}$ & 105 & $3 \cdot 856$ & 103 & $3 \cdot 512$ & $\mathrm{p}=0 \cdot 867$ & $\begin{array}{l}-0.34(-4 \cdot 53 \\
\text { to } 3 \cdot 84)\end{array}$ \\
\hline
\end{tabular}

Placebo and IPT intervention arms both contained 15 schools.

* Total number of correctly answered questions in a multiple-choice exam, specific to curriculum taught in each year group.

${ }^{\dagger}$ Crude estimates account for the cluster-randomised trial design.

Adjusted for stratified, cluster-randomised, trial design.

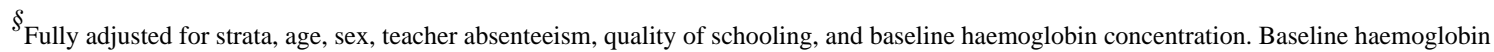
concentration was not available for all children. Social science exams were not carried out at baseline.

"Data available for children in 14 schools in the placebo arm. 